\title{
Registro Español de Trasplante Cardiaco: XXVI Informe Oficial de la Sección de Insuficiencia Cardiaca y Trasplante Cardiaco de la Sociedad Española de Cardiología (1984-2014)
}

\author{
Francisco González-Vílchez ${ }^{\text {a,b }}$, Javier Segovia Cubero ${ }^{\text {c }}$, Luis Almenar ${ }^{\text {d }}$, María G. \\ Crespo-Leiro e , José M. Arizón ${ }^{\mathrm{f}}$, Adolfo Villa ${ }^{\mathrm{g}}$, Juan Delgado ${ }^{\mathrm{h}}$, Eulalia Roig ${ }^{\mathrm{i}}$, Ernesto \\ Lage $^{\mathrm{j}}$, José González-Costello ${ }^{\mathrm{k}}$
}

\author{
${ }^{a}$ Registro Español de Trasplante Cardiaco, Sección de Insuficiencia Cardiaca y Trasplante Cardiaco, Sociedad \\ Española de Cardiología, Madrid, España \\ ${ }^{b}$ Servicio de Cardiología, Hospital Universitario Marqués de Valdecilla, Instituto de Investigación Marqués de \\ Valdecilla (IDIVAL), Santander, Cantabria, España \\ ${ }^{c}$ Servicio de Cardiología, Clínica Puerta de Hierro, Majadahonda, Madrid, España \\ ${ }^{d}$ Servicio de Cardiología, Hospital Universitario y Politécnico La Fe, Valencia, España \\ ${ }^{e}$ Servicio de Cardiología, Complejo Hospitalario Universitario de A Coruña, Instituto de Investigación Biomédica \\ de A Coruña (INIBIC), A Coruña, España \\ ${ }^{f}$ Servicio de Cardiología, Hospital Universitario Reina Sofía, Córdoba, España \\ ${ }^{g}$ Servicio de Cardiología (Adultos), Hospital Universitario Gregorio Marañón, Madrid, España \\ ${ }^{h}$ Hospital Universitario 12 de Octubre, Madrid, España \\ ${ }^{i}$ Hospital Universitario de la Santa Creu i Sant Pau, Barcelona, España \\ ${ }^{j}$ Hospital Universitario Virgen del Rocío, Sevilla, España \\ ${ }^{k}$ Hospital Universitario de Bellvitge, L'Hospitalet de Llobregat, Barcelona, España
}

\begin{abstract}
Resumen
Introducción y objetivos. Se presentan las características y resultados del trasplante cardiaco en España desde que empezó su actividad en mayo de 1984.

Métodos. Se realiza un análisis descriptivo de las características de los receptores, los donantes, el procedimiento quirúrgico y los resultados de los trasplantes cardiacos realizados en España hasta el 31 de diciembre de 2014.

Resultados. Durante 2014 se han realizado 266 procedimientos, con lo que la serie histórica consta de 7.289 trasplantes. El análisis temporal confirma un empeoramiento significativo del perfil clínico de los receptores (mayor porcentaje de pacientes añosos, con insuficiencia renal grave, diabetes insulinodependiente, cirugía cardiaca previa y ventilación mecánica), de los donantes (mayor porcentaje de donantes añosos y con mayor discordancia de peso) y del procedimiento (mayor porcentaje de trasplante urgente, que en 2014 alcanza el 41,4\%, y con tiempo de isquemia $>240 \mathrm{~min}$ ). El uso de dispositivos de asistencia mecánica ha disminuido respecto a 2013, y en 2014 supone el 18,8\% del total de pacientes. La supervivencia a 1, 5, 10 y 15 años es del 76, el 65, el 52 y el $38 \%$ respectivamente, y permanece estable desde 1995.

Conclusiones. La actividad de trasplante cardiaco en España permanece estable en los últimos años, con alrededor de 250 procedimientos al año. A pesar del claro empeoramiento de las características de donantes, receptores y tiempos quirúrgicos, se mantienen unos resultados en mortalidad comparables a los del entorno y se confirma un uso creciente de los dispositivos de asistencia circulatoria antes del trasplante.
\end{abstract}

Palabras clave

Trasplante cardiaco; Registro; Supervivencia. 


\section{INTRODUCCIÓN}

Desde 1991, el Registro Español de Trasplante Cardiaco viene publicando la descripción de las características clínicas y quirúrgicas y los resultados globales de los procedimientos de trasplante cardiaco que se realizan en España ${ }^{1-25}$. El presente artículo describe los datos referentes a la población trasplantada hasta el 31 de diciembre de 2014. Como ya es conocido, la mayor fortaleza del Registro Español de Trasplante Cardiaco reside en la inclusión y actualización exhaustiva de todos los procedimientos de trasplante cardiaco realizados en todos los hospitales españoles desde mayo de 1984, independientemente de sus características y resultados. Además, la recogida de datos se realiza prospectivamente en una base de datos común consensuada y actualizada por todos los grupos.

\section{MÉTODOS}

\section{Pacientes y centros}

De los 19 centros que han aportado datos al Registro Español de Trasplante Cardiaco, actualmente permanecen activos 18 (tabla 1). Dos centros se dedican únicamente al trasplante pediátrico y otros tres mantienen actividad tanto en trasplante pediátrico como del adulto. El número de procedimientos realizados anualmente se resume en la figura 1. El total de la serie consta de 7.289 procedimientos. En 12 casos se ha producido pérdida de datos, incluida información sobre el seguimiento. Estos no se incluyeron en los análisis, y el tamaño muestral finalmente quedó formado por 7.277 casos. De los 266 procedimientos realizados en 2014, 12 casos (4,5\%) se realizaron en pacientes pediátricos (edad < 16 años). Los tipos de procedimientos realizados en 2014 y en la serie total se resumen en la tabla 2.

Tabla 1. Centros participantes (por orden de realización del primer trasplante) en el Registro Español de Trasplante Cardiaco (1984-2014)

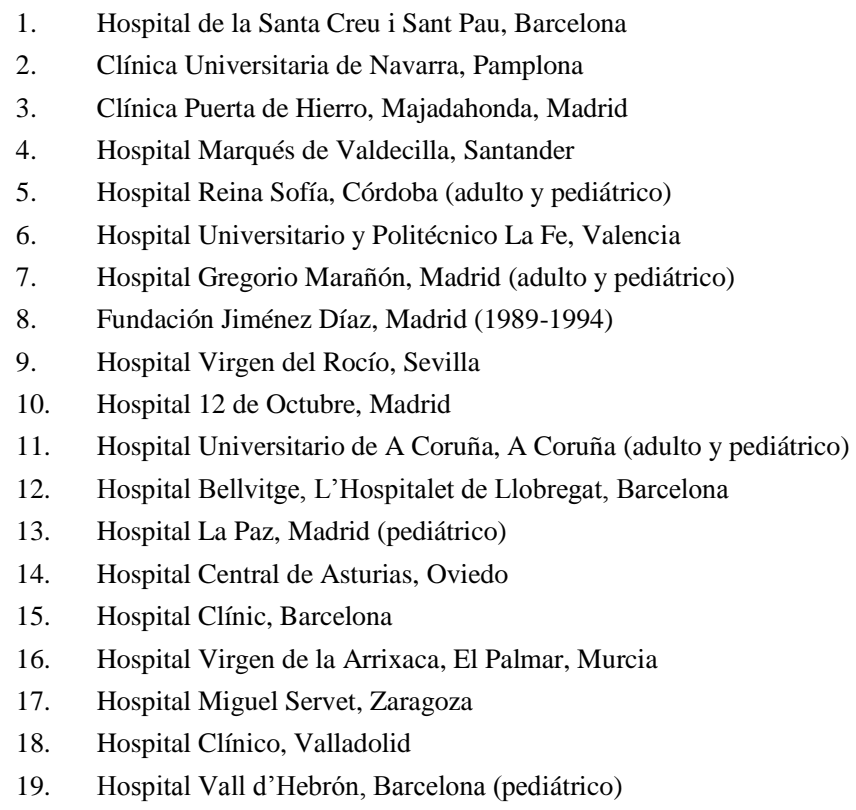




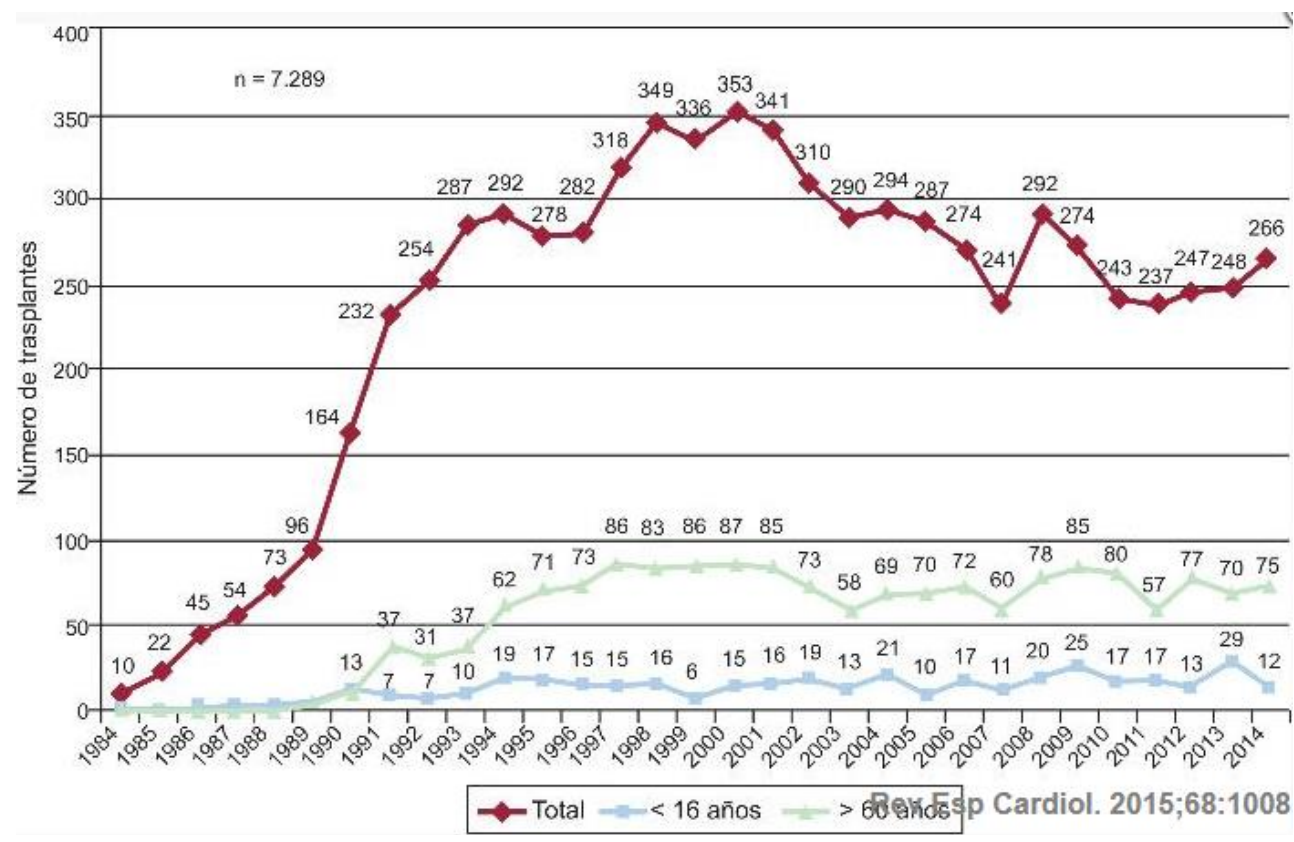

Figura 1. Número anual de trasplantes (1984-2014) total y por grupos de edad.

Tabla 2. Registro Español de Trasplante Cardiaco (1984-2014). Tipo de procedimiento

\begin{tabular}{lcc}
\hline Procedimiento & 2014 & $1984-2014$ \\
\hline & & \\
Trasplante cardiaco de novo & 255 & 6.957 \\
Retrasplante & 5 & 171 \\
Retrasplante combinado & 1 & 6 \\
Trasplantes combinados & 6 & 143 \\
Corazón-pulmón & 3 & 72 \\
Corazón-riñón & $3^{*}$ & 61 \\
Corazón-hígado & - & 8 \\
Total & 266 & 7.277 \\
& & \\
\hline
\end{tabular}

* Incluye el retrasplante combinado.

\section{Procedimientos}

La base de datos consta de 175 variables clínicas preestablecidas de manera consensuada por todos los grupos y que recogen datos de receptor, donante, técnica quirúrgica, inmunosupresión y seguimiento. Desde 2013 los datos se introducen y se actualizan en formato electrónico en tiempo real mediante una aplicación disponible en internet específicamente diseñada para tal propósito. El soporte de la base de datos es un archivo de Microsoft Excel. Este procedimiento sustituye al anterior, en el que cada centro enviaba los datos al director del registro en formato Microsoft Access mediante correo electrónico. Una CRO (contract research organization) externa -actualmente ODDS, S.L.- se encarga del mantenimiento de la base de datos, el control de calidad y el análisis estadístico.

La aprobación por el comité ético, la auditoría y el registro en el Ministerio de Sanidad se han realizado según lo dispuesto en la Ley Orgánica de Protección de Datos 15/1999. 


\section{Estadística}

Las variables cuantitativas continuas se presentan como media \pm desviación estándar y las categóricas, como porcentaje. Los resultados se categorizan según el año del trasplante dividiendo la muestra total en tres grupos (1984-1993, 1994-2003 y 2004-2014). En algunas variables (como edad del donante, trasplantes urgentes y tiempo de isquemia), también se analizaron los datos anuales de toda la serie. Las diferencias entre grupos se analizan mediante un test no paramétrico para la tendencia temporal (tau de Kendall) en el caso de variables categóricas y test de análisis de la varianza con ajuste polinómico para las variables cuantitativas. Las curvas de supervivencia se han calculado mediante el test de Kaplan-Meier y la comparación entre ellas, con el método de log rank test. Se ha considerado diferencia significativa en las comparaciones con valor de $\mathrm{p}<0,05$.

\section{RESULTADOS}

\section{Características de los receptores}

En 2014, los receptores tenían $50 \pm 16(0,02-73)$ años de edad; el 75\% eran varones, con diagnósticos basales mayoritarios de miocardiopatía isquémica (25,9\%), dilatada no isquémica $(27,8 \%)$, miocardiopatía de origen valvular (4,5\%) y otras etiologías $(41,7 \%)$. Las características de los pacientes trasplantados por periodo de trasplante se resumen en la tabla 3. Se observan tendencias significativas a mayor edad de los receptores, sexo femenino y etiologías no usuales de la cardiopatía de base y un aumento de las condiciones previas al trasplante de reconocido efecto pronóstico como la diabetes insulinodependiente y la infección, la cirugía cardiaca y la ventilación mecánica previas al trasplante. La frecuencia del retrasplante se mantiene estable en torno al 2,4\% en el periodo 1984-2014. Por el contrario, hay una disminución significativa de las resistencias vasculares pulmonares previas al trasplante a lo largo de la serie temporal. 
Tabla 3. Características del receptor en el Registro Español de Trasplante Cardiaco (1984-2014)

\begin{tabular}{|c|c|c|c|c|c|}
\hline & $\begin{array}{l}1984-1993 \\
(\mathrm{n}=1.230)\end{array}$ & $\begin{array}{l}1994-2003 \\
(n=3.148)\end{array}$ & $\begin{array}{l}2004-2014 \\
(n=2.899)\end{array}$ & $\mathrm{p}$ (tendencia) & $\begin{array}{c}2014 \\
(n=266)\end{array}$ \\
\hline Edad (años) & $46,7 \pm 13,4$ & $50,4 \pm 14,6$ & $49,6 \pm 16,5$ & $<0,001$ & $49,9 \pm 15,8$ \\
\hline$<16$ años & 3,9 & 4,8 & 6,6 & $<0,001$ & 4,5 \\
\hline$>60$ años & 10,0 & 24,3 & 27,4 & $<0,001$ & 28,2 \\
\hline Sexo (varones) & 85,8 & 81,1 & 76,0 & $<0,001$ & 75,2 \\
\hline IMC & $24,2 \pm 4$ & $25,0 \pm 4,5$ & $24,9 \pm 4,7$ & $<0,001$ & $24,8 \pm 4,3$ \\
\hline Etiología de base & & & & $<0,001$ & \\
\hline Dilatada no isquémica & 39,8 & 34,3 & 27,1 & & 27,8 \\
\hline Isquémica & 30,8 & 30,0 & 26,0 & & 25,9 \\
\hline Valvular & 10,5 & 7,6 & 7,4 & & 4,5 \\
\hline Otras & 24,9 & 28,1 & 39,6 & & 41,7 \\
\hline$R V P(U W)$ & $2,6 \pm 1,8$ & $2,3 \pm 1,8$ & $2,4 \pm 2,1$ & $<0,001$ & $2,2 \pm 1,3$ \\
\hline Creatinina $>2 \mathrm{mg} / \mathrm{dl}$ & 7,0 & 6,1 & 7,9 & 0,131 & 5,8 \\
\hline Bilirrubina $>2 \mathrm{mg} / \mathrm{dl}$ & 19,7 & 17,8 & 17,8 & 0,35 & 16,8 \\
\hline Diabetes insulinodependiente & 8,5 & 12,9 & 17,3 & $<0,001$ & 21,4 \\
\hline EPOC moderada-grave & 9,3 & 11,2 & 9,8 & 0,109 & 13,7 \\
\hline Infección previa & 4,0 & 9,4 & 13,8 & $<0,001$ & 14,0 \\
\hline Cirugía cardiaca previa & 25,3 & 26,5 & 29,1 & 0,024 & 30,1 \\
\hline Retrasplante cardiaco & 2,8 & 2,1 & 2,6 & 0,84 & 2,3 \\
\hline Ventilación mecánica previa al trasplante & 8,3 & 10,3 & 15,7 & $<0,001$ & 11,7 \\
\hline Trasplante urgente & 18,1 & 23,6 & 35,1 & $<0,001$ & 41,4 \\
\hline
\end{tabular}

IMC: índice de masa corporal; EPOC: enfermedad pulmonar obstructiva crónica; RVP: resistencias vasculares pulmonares. Los valores expresan media \pm desviación estándar o porcentajes.

Aunque en 2014 se ha producido una ligera disminución de los trasplantes con carácter de urgencia respecto a 2013, hay una fuerte tendencia al incremento de este tipo de trasplantes a lo largo de la serie temporal ( $\mathrm{p}<0,00001$ ) (figura 2). Concomitantemente, hay un incremento significativo ( $<<0,00001)$ del uso de dispositivos mecánicos de asistencia circulatoria más allá del tradicional balón de contrapulsación, que aparecen de manera significativa en la última década (figura 3). El uso de oxigenador extracorpóreo de membrana (ECMO) y de dispositivos de asistencia ventricular tanto pulsátil como de flujo continuo es particularmente evidente a partir de 2009 (figura 4). Entre 2009 y 2014, el uso de ECMO se ha duplicado y el de asistencia de flujo continuo ha aumentado exponencialmente (del 2,0\% en 2009 al 15,7\% en 2014). 


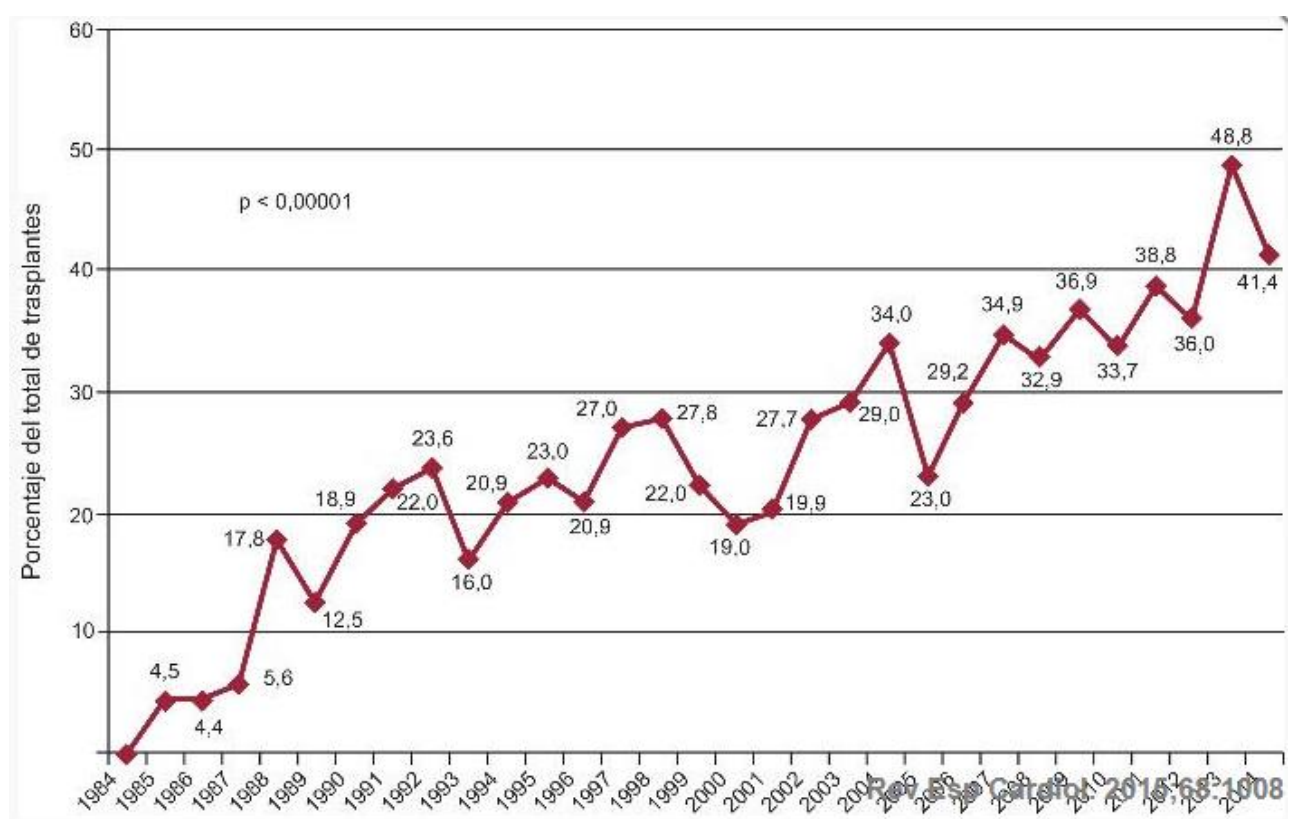

Figura 2. Porcentaje anual de trasplantes urgentes sobre la población total (1984-2014).

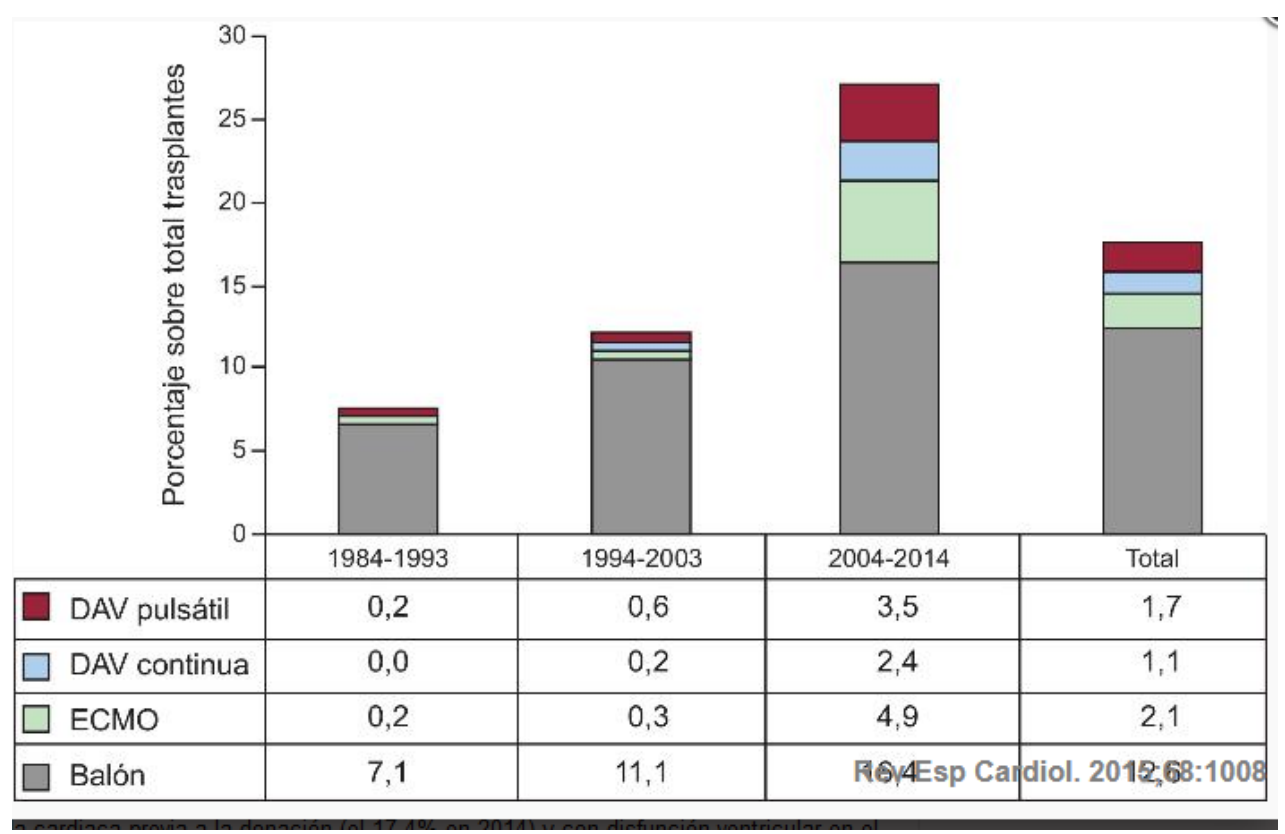

Figura 3. Distribución del tipo de asistencia circulatoria previa al trasplante por periodos. DAV: dispositivo de asistencia ventricular; ECMO: oxigenador extracorpóreo de membrana. 


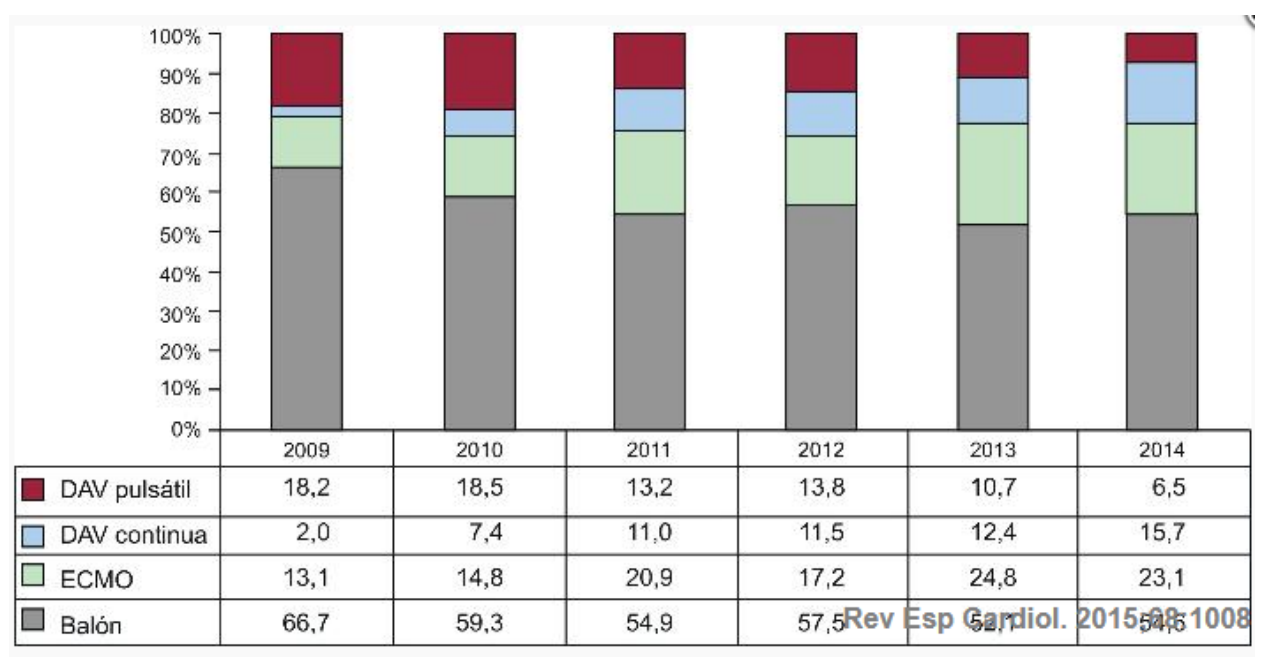

Figura 4. Distribución del tipo de asistencia circulatoria previa al trasplante en el periodo 2009-2014. DAV: dispositivo de asistencia ventricular; ECMO: oxigenador extracorpóreo de membrana.

\section{Características de los donantes y tiempo de isquemia}

Las características de los donantes según el intervalo de tiempo y en 2014 se resumen en la tabla 4. La edad del donante ha ido incrementándose significativamente a lo largo de la serie, con un porcentaje de donantes considerados subóptimos (edad > 45 años) > 50\% en 2014 (figura 5). También se aprecia el aumento progresivo de los donantes de sexo femenino y del porcentaje de trasplantes realizados a receptor varón con donante mujer (el 22,9\% en 2014), con parada cardiaca previa a la donación (el 17,4\% en 2014) y con disfunción ventricular en el ecocardiograma previo a la extracción (el 3,3\% en 2014). Asimismo, hay un aumento de los donantes fallecidos por accidente cerebrovascular en detrimento de los fallecidos por traumatismo (figura 6). 
Tabla 4. Características de los donantes y tiempos de isquemia en el Registro Español de Trasplante Cardiaco (1984-2014)

\begin{tabular}{|c|c|c|c|c|c|}
\hline & $\begin{array}{l}1984-1993 \\
(\mathrm{n}=1.230)\end{array}$ & $\begin{array}{l}1994-2003 \\
(n=3.148)\end{array}$ & $\begin{array}{l}2004-2014 \\
(n=2.899)\end{array}$ & $\mathrm{p}$ (tendencia) & $\begin{array}{c}2014 \\
(n=266)\end{array}$ \\
\hline Edad (años) & $26,5 \pm 10,3$ & $31,3 \pm 12,9$ & $37,4 \pm 14,6$ & 0,067 & $43,6 \pm 14,9$ \\
\hline Edad $>45$ años & 7,6 & 19,3 & 37,3 & $<0,001$ & 53,8 \\
\hline Sexo (varones) & 78,4 & 70,9 & 65,7 & $<0,001$ & 62,0 \\
\hline Donante mujer-receptor varón & 17,8 & 20,9 & 21,2 & 0,045 & 22,9 \\
\hline Peso $(k g)$ & $69,4 \pm 13,4$ & $70,1 \pm 16,1$ & $72,6 \pm 18,0$ & 0,007 & $75,0 \pm 18,3$ \\
\hline Peso receptor/donante & $1,0 \pm 0,2$ & $1,0 \pm 0,3$ & $1,0 \pm 1,0$ & $<0,001$ & $1,0 \pm 0,9$ \\
\hline Peso receptor/donante $>1,20$ & 13,3 & 15,8 & 11,1 & $<0,001$ & 9,4 \\
\hline Peso receptor/donante $<0,8$ & 13,8 & 14,7 & 19,7 & $<0,001$ & 21,1 \\
\hline Parada cardiaca pretrasplante ${ }^{\text {a }}$ & 3,0 & 7,2 & 11,1 & $<0,001$ & 17,4 \\
\hline Ecocardiograma predonación ${ }^{\mathrm{b}}$ & & & & $<0,001$ & \\
\hline No realizado & 52,5 & 21,0 & 6,0 & & 1,4 \\
\hline Normal & 47,1 & 77,7 & 91,4 & & 95,3 \\
\hline Disfunción general ligera & 0,3 & 1,2 & 2,7 & & 3,3 \\
\hline Tiempo de isquemia (min) & $160,8 \pm 61,4$ & $184,8 \pm 61,7$ & $205,4 \pm 64,3$ & 0,06 & $199,6 \pm 72,6$ \\
\hline$\leq 120 \min$ & 27,0 & 18,0 & 11,5 & $<0,001$ & 15,0 \\
\hline $121-180 \mathrm{~min}$ & 36,2 & 28,3 & 22,2 & & 22,6 \\
\hline $181-240 \mathrm{~min}$ & 28,1 & 36,7 & 38,7 & & 35,0 \\
\hline$>240 \min (\%)$ & 8,7 & 17,1 & 27,6 & & 27,4 \\
\hline
\end{tabular}

Los valores expresan media \pm desviación estándar o porcentajes.

${ }^{a}$ Sobre 3.621 trasplantes.

${ }^{\mathrm{b}}$ Sobre 5.959 trasplantes.

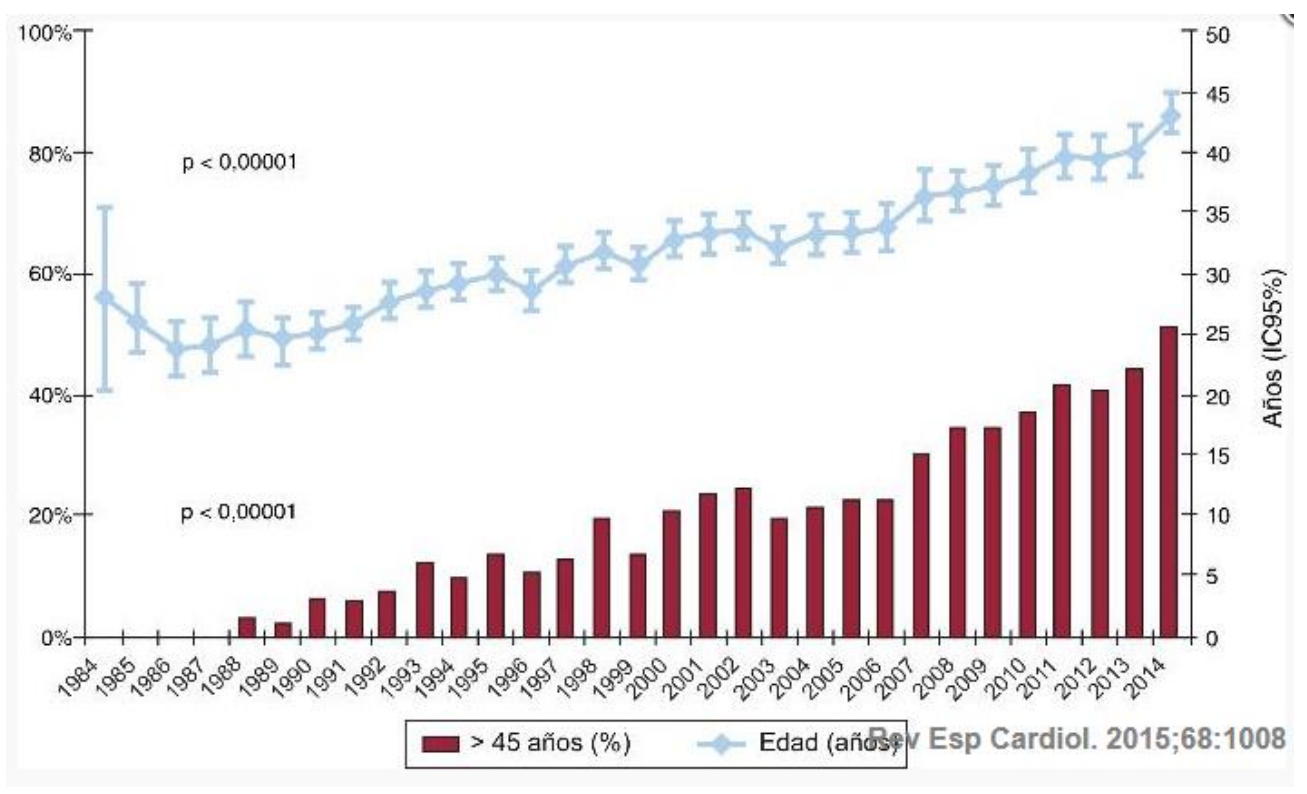

Figura 5. Evolución anual de edad del donante y porcentaje de donantes con edad mayor de 45 años (1984-2014) IC95\%: intervalo de confianza del 95\%. 


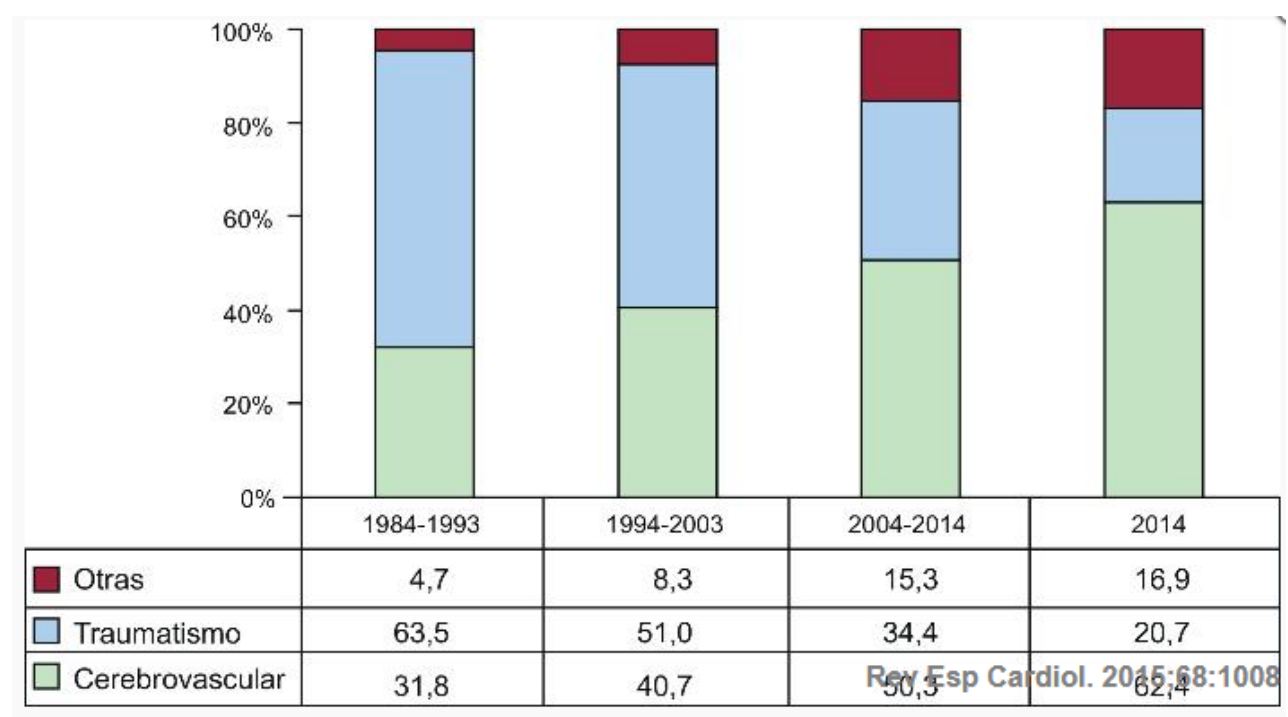

Figura 6. Evolución por periodos de las causas de muerte de los donantes cardiacos.

El tiempo de isquemia se ha incrementado a lo largo de la serie temporal. En 2014, tal como ocurrió en la década previa, más de un cuarto de los pacientes fueron trasplantados con un tiempo de isquemia > 240 min (tabla 4, figura 7).

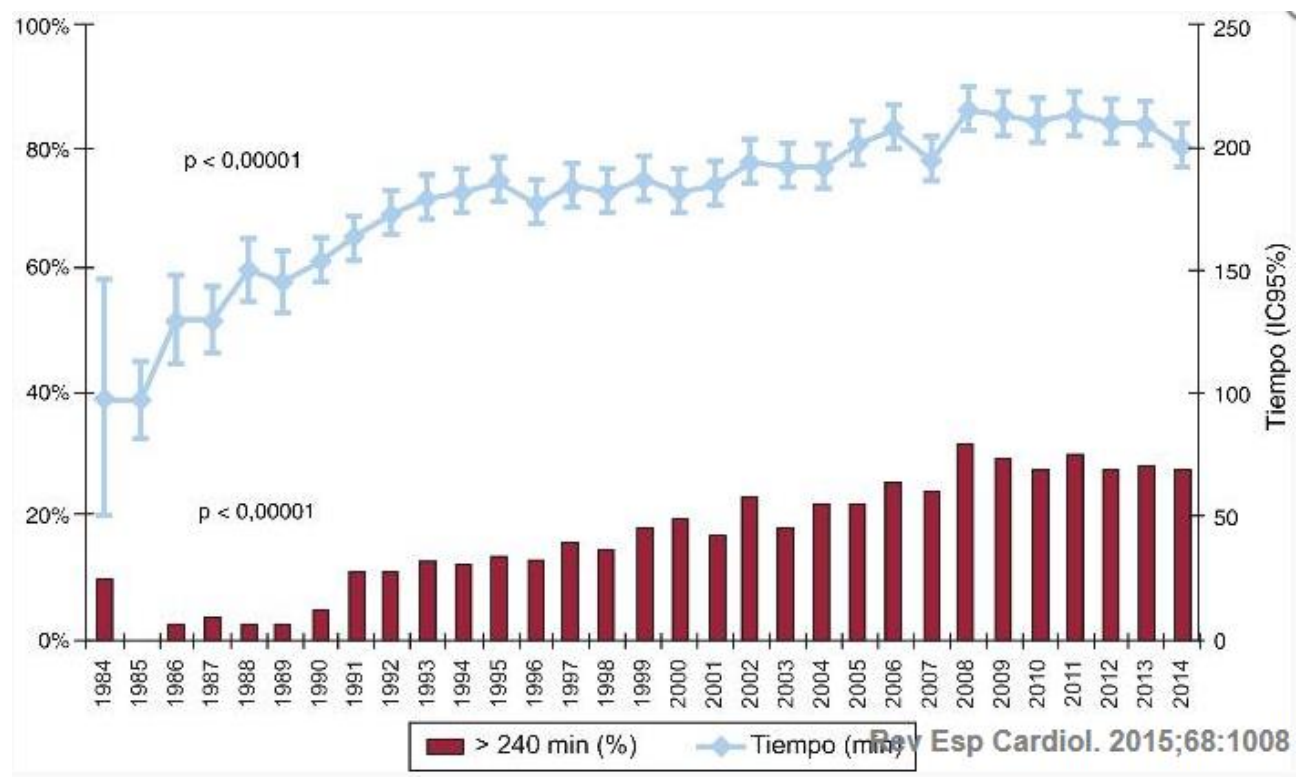

Figura 7. Evolución anual de tiempo de isquemia y porcentaje de tiempo de isquemia > 240 min (1984-2014) IC95\%: intervalo de confianza del $95 \%$. 


\section{Inmunosupresión}

En 2014, el 87,9\% de los receptores recibieron algún tratamiento inmunosupresor de inducción, en su inmensa mayoría basiliximab (84,5\%). En la figura 8 se aprecia cómo la inducción ha ido incrementándose progresivamente hasta su uso mayoritario actual. En el periodo 2009-2014, se indujo al $80 \%$ de los pacientes con inhibidores de la interleucina 2 (basiliximab o daclizumab, fundamentalmente el primero), sustituyendo al uso mayoritario del OKT3 de los periodos anteriores.

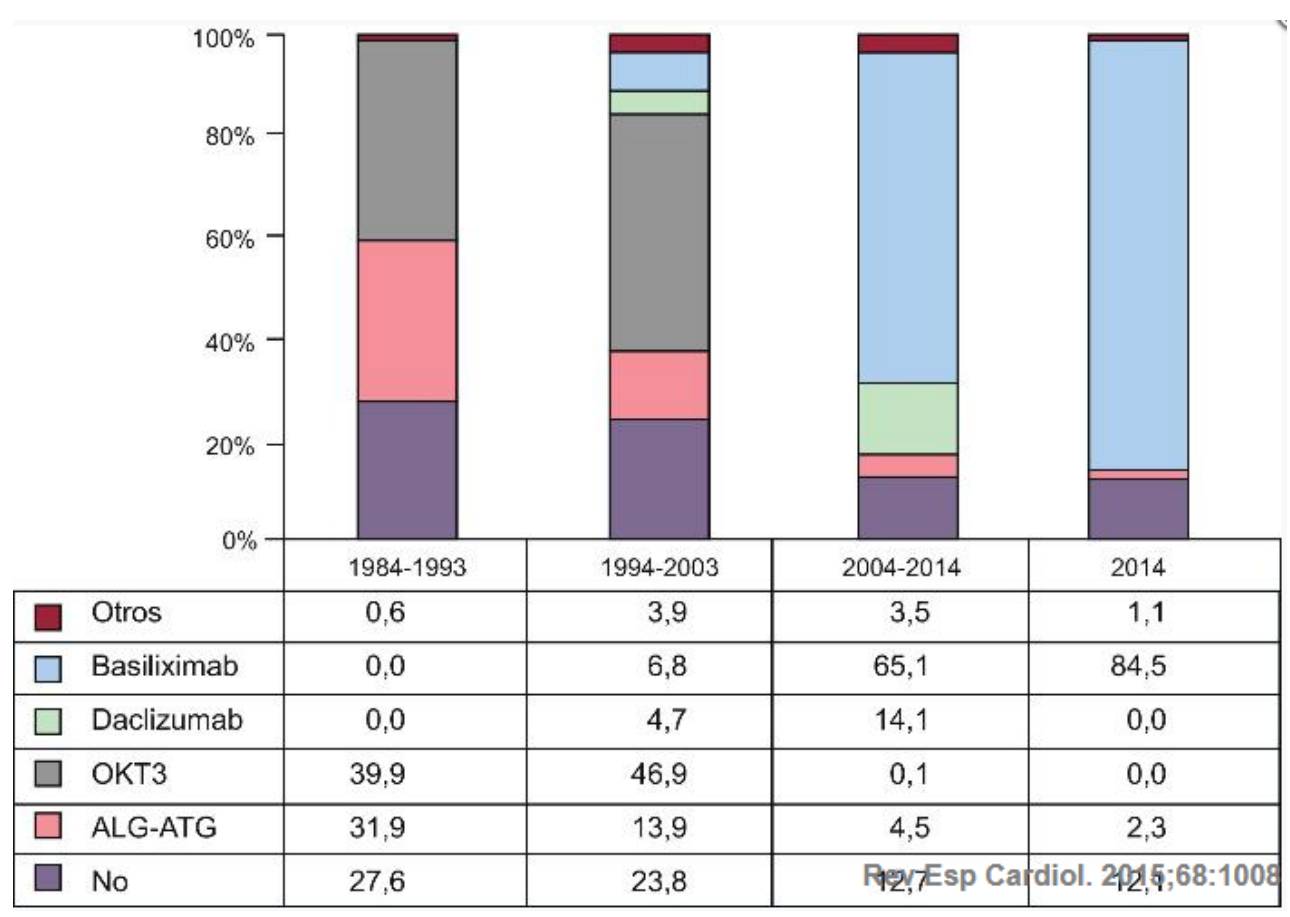

Figura 8. Fármacos utilizados en la inmunosupresión de inducción. ALG: globulina antilinfocitaria; ATG: globulina antitimocitaria.

La inmunosupresión de inicio en 2014 se realizó mayoritariamente con tacrolimus $(86,7 \%)$ como inhibidor de la calcineurina, micofenolato mofetilo o ácido micofenólico $(96,1 \%)$ como antiproliferativo y esteroides (96,9\%). En la figura 9 se resumen los fármacos usados en la inmunosupresión inicial y al final del seguimiento para la serie total. En un seguimiento promedio de 7 años, el 61,6\% de los pacientes continuaban en tratamiento con corticoides. Como se puede apreciar, tacrolimus tiende a igualarse con la ciclosporina en la inmunosupresión al final del seguimiento, a pesar del predominio de la segunda en las pautas de inmunosupresión al inicio del trasplante. La azatioprina mantiene un uso apenas testimonial y, llamativamente, el $27,9 \%$ de los pacientes estaba en tratamiento con inhibidores de la mTOR (everolimus o sirolimus) en el último seguimiento. 


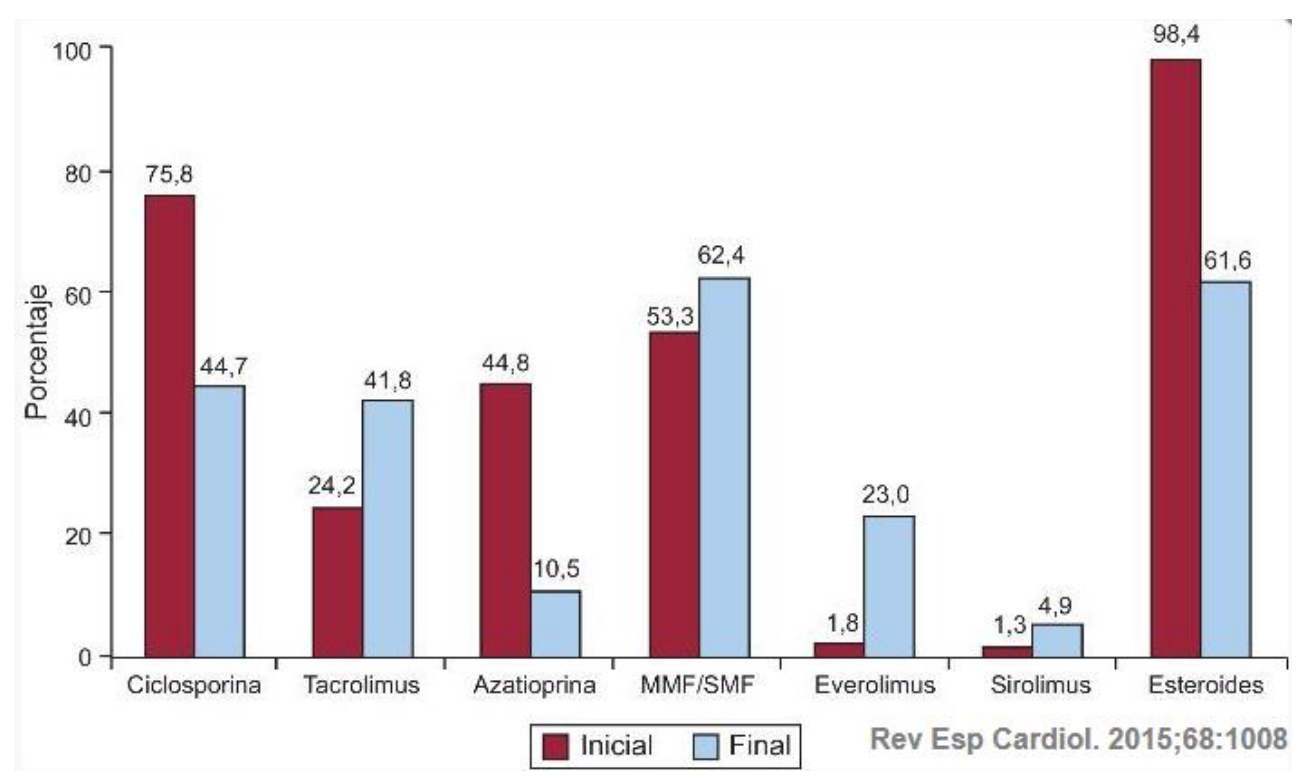

Figura 9. Inmunosupresión inicial y de mantenimiento en el total de la serie (1984-2014). Variaciones evolutivas según el tipo de fármaco: al inicio del trasplante y al final del seguimiento. MMF: micofenolato mofetilo; SMF: micofenolato sódico.

La evolución anual del uso de los distintos inhibidores de la calcineurina y antimitóticos se muestra en las figura 10 y figura 11 respectivamente. El uso de tacrolimus igualó al uso de ciclosporina en 2005, manteniendo una tendencia ascendente desde entonces para convertirse en el inhibidor de la calcineurina predominante en la inmunosupresión de inicio. Similar tendencia se observa entre micofenolato mofetilo y azatioprina, cuyo uso se igualó entre 1999 y 2001; a partir de 2009 el micofenolato pasó a ser el antimitótico predominante en la inmunosupresión de inicio, relegando a la azatioprina a un uso mínimo. La evolución anual del uso de inhibidores de mTOR (sirolimus, everolimus) en la inmunosupresión de inicio se muestra en la figura 12. Estos fármacos se usaron inicialmente en un porcentaje apreciable entre los años 2005 y 2007, y después decayeron hasta un porcentaje mínimo.

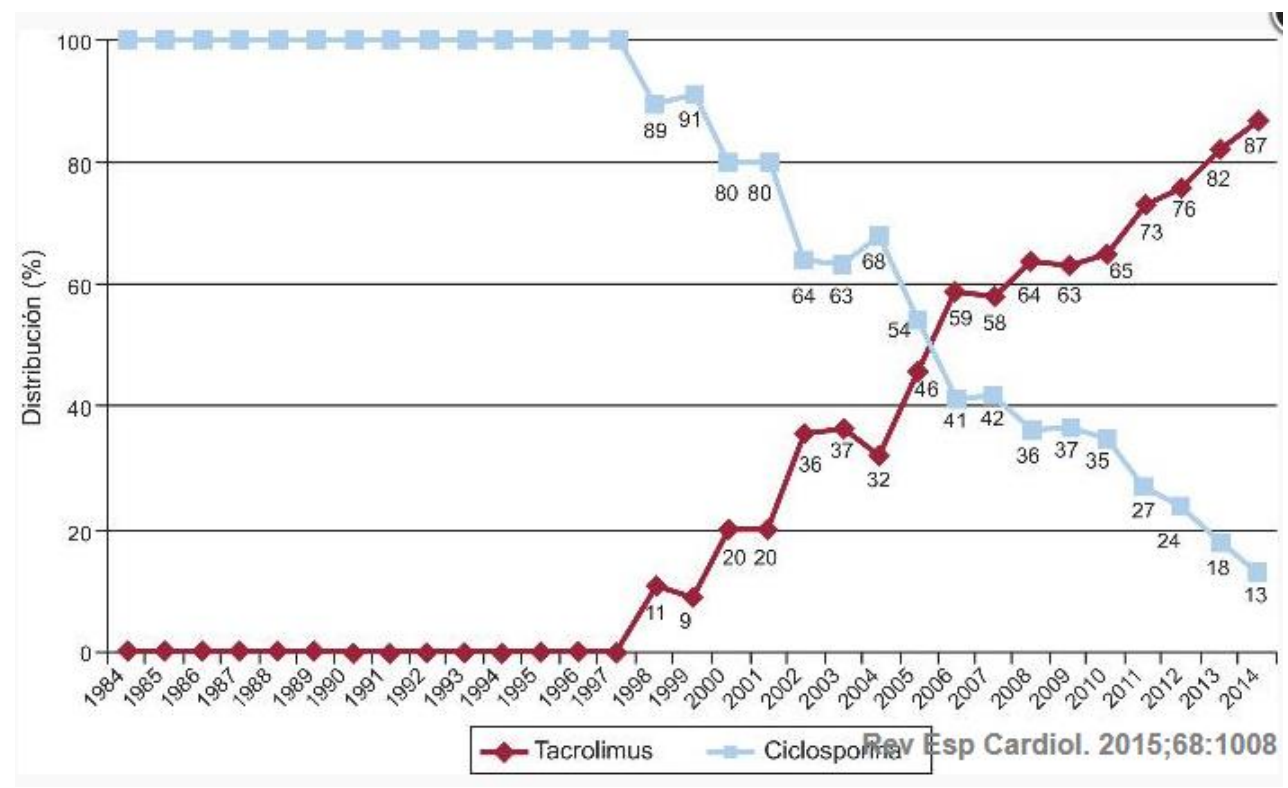

Figura 10. Evolución anual del uso de inhibidores de la calcineurina (ciclosporina y tacrolimus) en la inmunosupresión de inicio en la muestra total (1984-2014). 


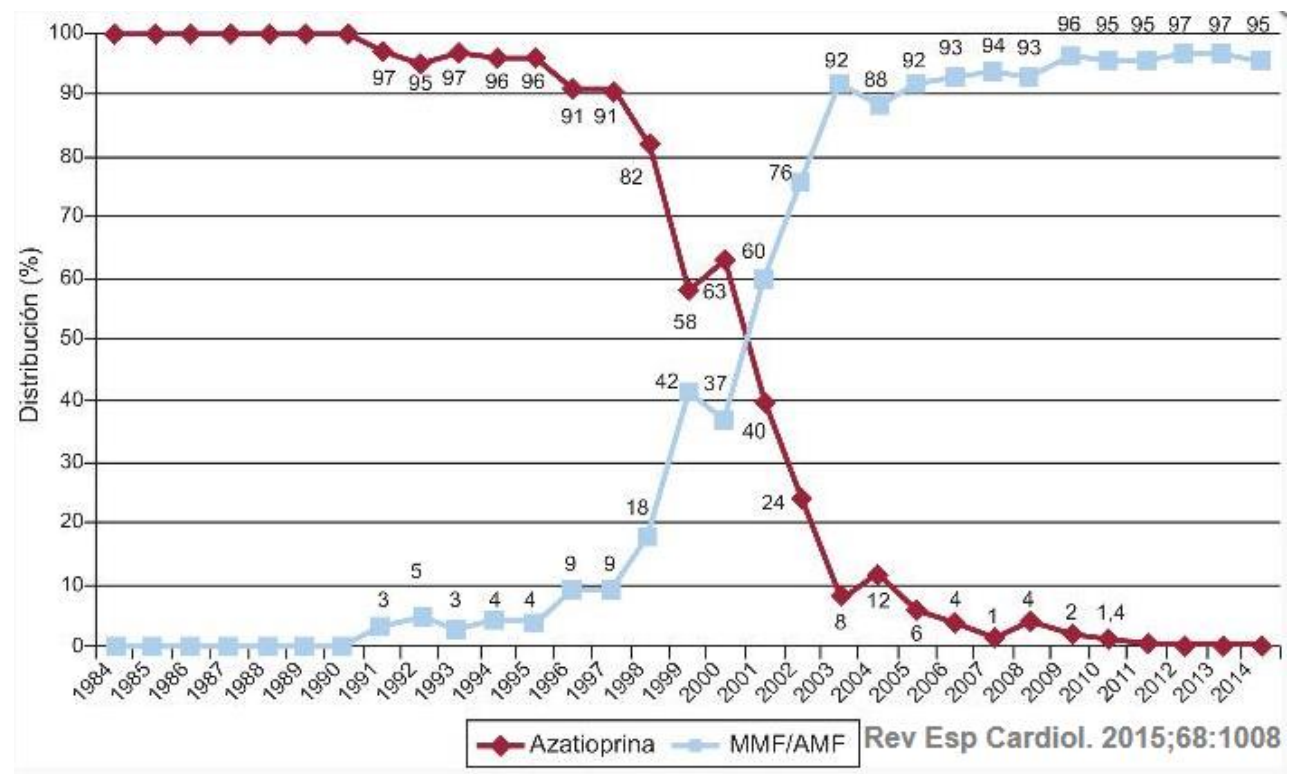

Figura 11. Evolución anual del uso de antimitóticos (azatioprina y micofenolato mofetilo/ácido micofenólico) en la inmunosupresión de inicio en la muestra total (1984-2014). AMF: ácido micofenólico; MMF: micofenolato mofetilo.

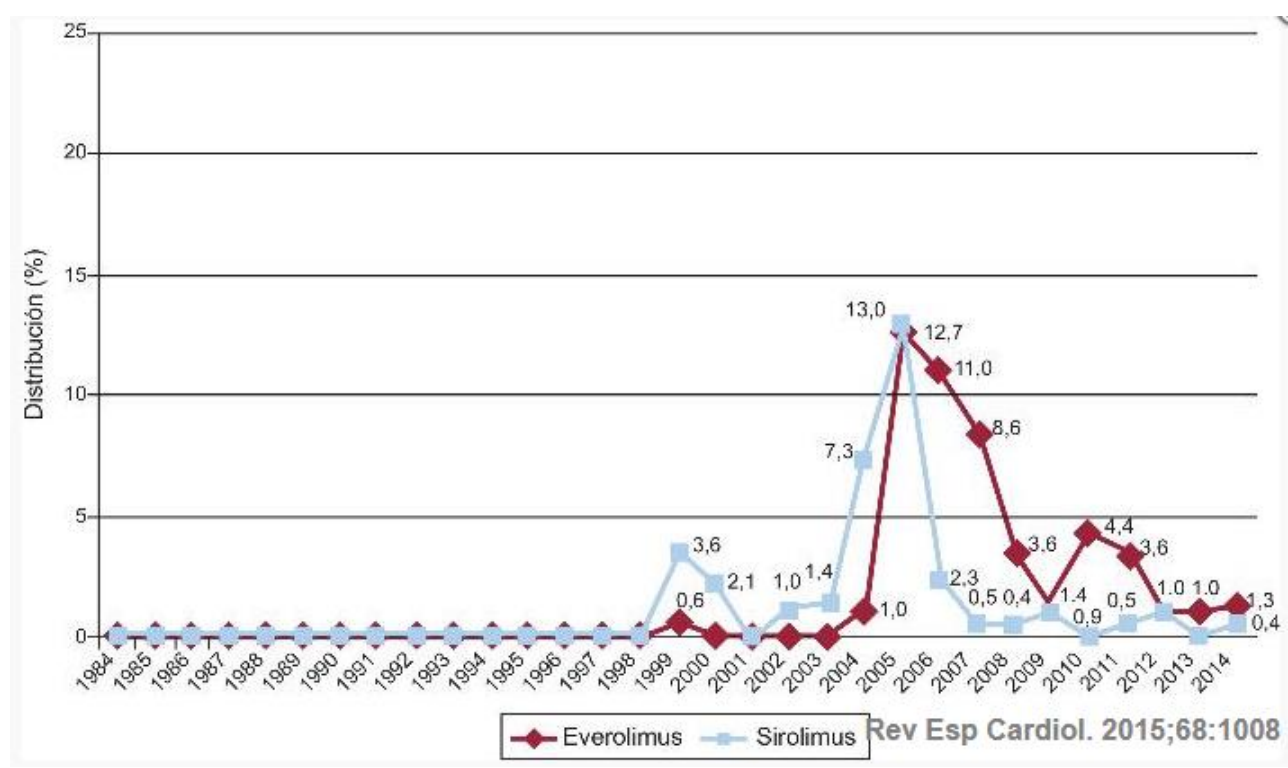

Figura 12. Evolución anual del uso de inhibidores de mTOR (sirolimus y everolimus) en la inmunosupresión de inicio en la muestra total (1984-2014). Las diferencias en los valores respecto a informes de años previos se deben al redondeo o a diferencias surgidas por la continua actualización de la base de datos por los grupos participantes. 


\section{Supervivencia}

Al 31 de diciembre de 2014, la supervivencia actuarial en el conjunto de la serie a 1, 5, 10, 15 y 20 años se resume en la figura 13. Esto supone una mortalidad promedio de 2-3\%/año aproximadamente después del primer año postrasplante, con una mediana de supervivencia de 10,9 años. Hubo diferencias significativas según la edad del receptor en el momento del trasplante y tipo de procedimiento. La supervivencia de los pacientes con menos de 16 años fue significativamente mejor que la de los pacientes con edad entre 16 y 60 años y la de estos con respecto a los pacientes mayores de 60 años (figura 14). Igualmente hubo diferencias muy significativas entre los trasplantes cardiacos solos, los trasplantes cardiacos combinados con trasplante renal, hepático o pulmonar y los retrasplantes (figura 15). La edad del donante mayor de 45 años afectó también y muy significativamente a la supervivencia (figura 16).

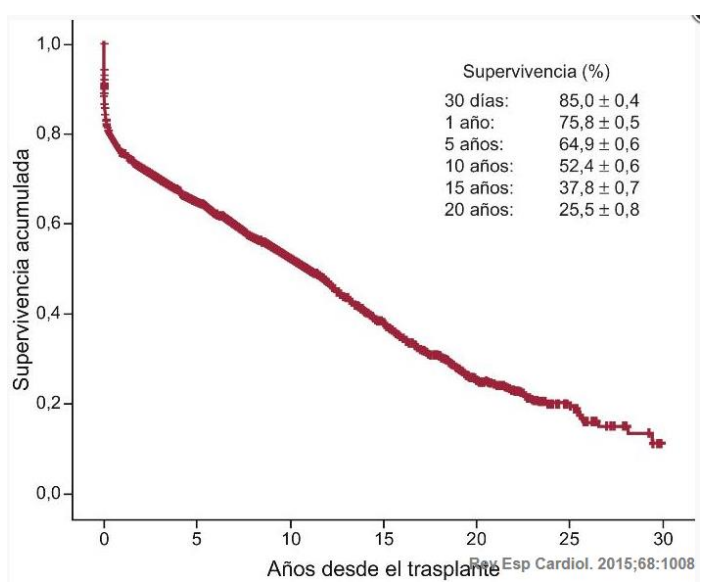

Figura 13. Curva de supervivencia general de toda la serie.

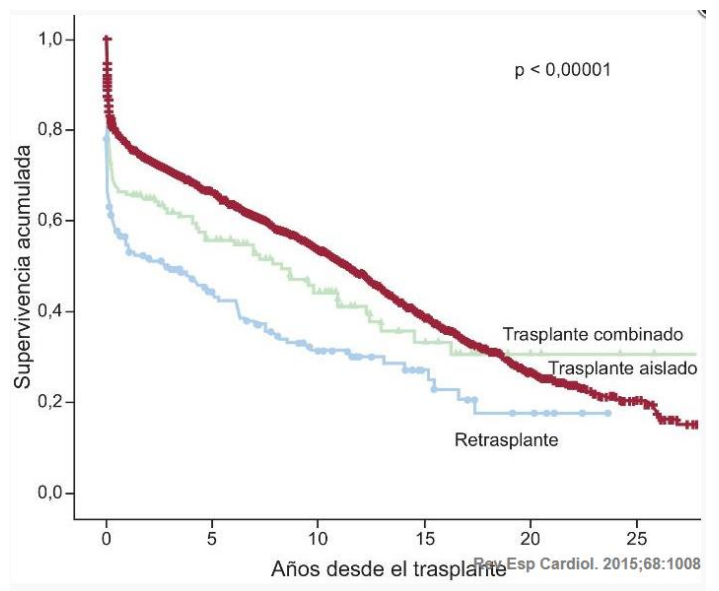

Figura 15. Comparación entre curvas de supervivencia de trasplante cardiaco solo, trasplante combinado con trasplante renal, hepático o pulmonar y retrasplante cardiaco.

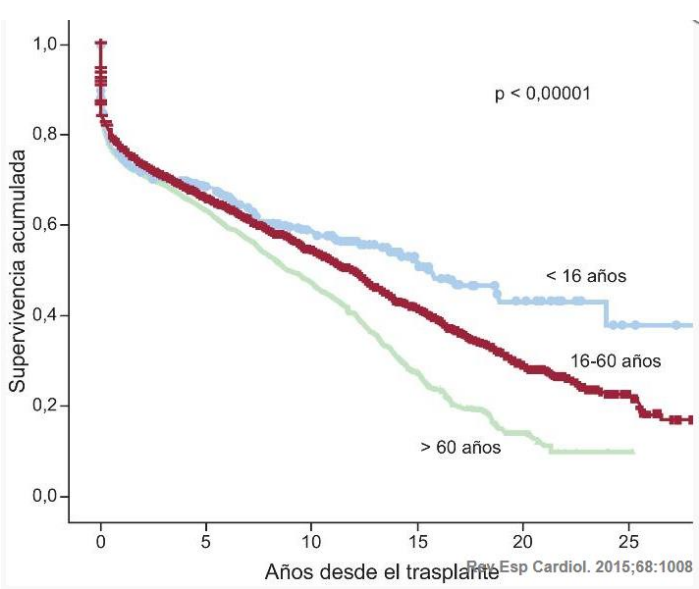

Figura 14. Comparación entre curvas de supervivencia según edad del receptor en el momento del trasplante $(<16,16-60$ y $>60$ años)

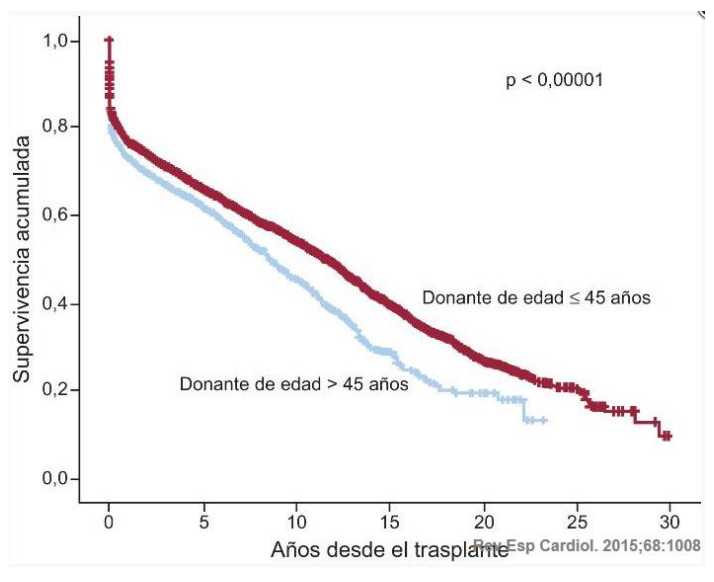

Figura 16. Comparación entre curvas de supervivencia de trasplante cardiaco según edad del donante. 
En la serie total, se observan diferencias muy significativas $(\mathrm{p}<0,00001)$ para la supervivencia entre los trasplantes realizados de manera electiva y los urgentes (figura 17). Analizando el periodo 2009-2014, en el cual el uso de dispositivos de asistencia mecánica se ha incrementado de manera apreciable, se observa que la peor supervivencia es la del trasplante urgente realizado con asistencia tipo ECMO, sin que haya diferencias significativas respecto al trasplante electivo en los trasplantes realizados con balón de contrapulsación o dispositivos de asistencia ventricular (figura 18). Las diferencias entre tipos de trasplante según el estado del paciente en el momento de la intervención se establecen en los primeros 6 meses después del procedimiento, con un recorrido paralelo de las curvas posteriormente.

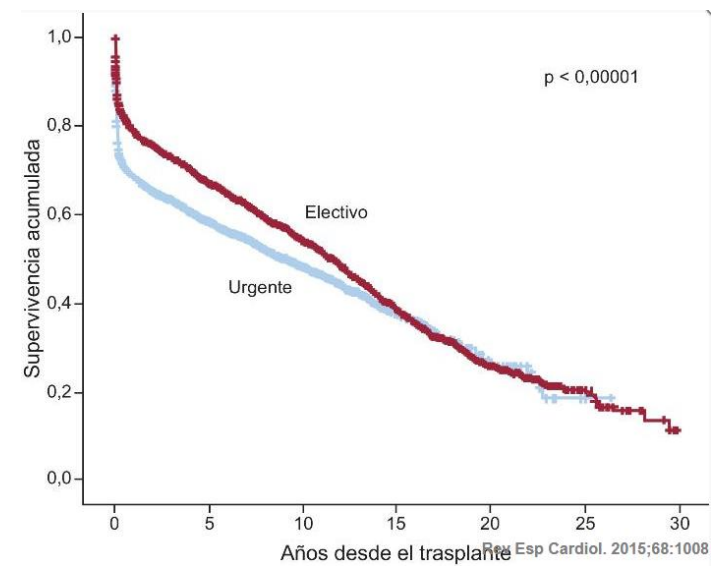

Figura 17. Comparación de curvas de supervivencia entre trasplantes electivos y urgentes.

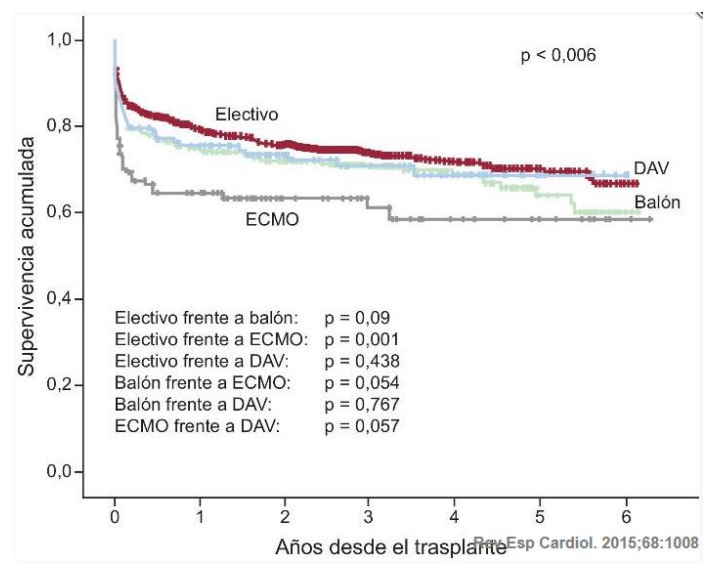

Figura 18. Comparación de curvas de supervivencia entre trasplantes electivos, urgentes sin asistencia ventricular y urgentes con asistencia ventricular (2009-2014). DAV: dispositivo de asistencia ventricular; ECMO: oxigenador extracorpóreo de membrana.

Después de la primera década (1984-1993) se evidencia una significativa mejora en la supervivencia a medio y largo plazo, mediada fundamentalmente por la menor mortalidad en etapas postrasplante precoces (figura 19). Para la última década (2004-2013) se observa una tendencia no significativa $(\mathrm{p}=0,064)$ a la mejora de la supervivencia a partir del tercer-cuarto año postrasplante respecto a la década inmediatamente anterior (1994-2003) (figura 19).

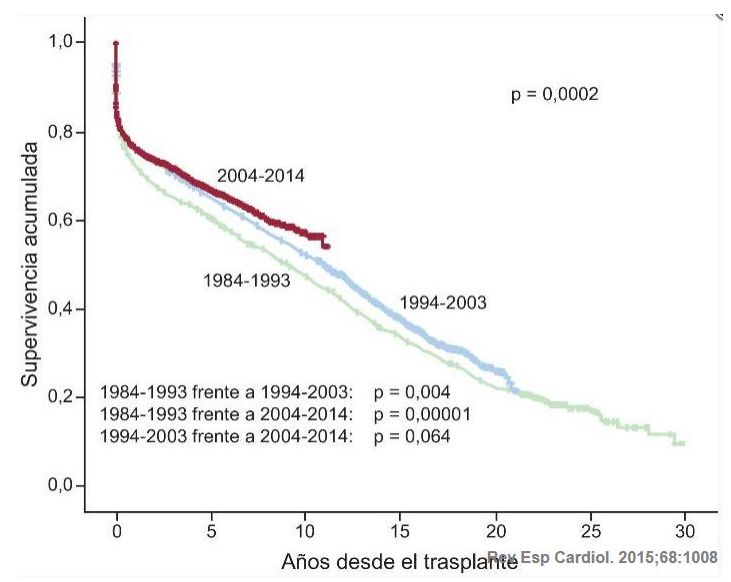

Figura 19. Comparación de curvas de supervivencia de la muestra total según el periodo de trasplante (intervalos de 10 años desde 1984). 


\section{Causas de fallecimiento}

En la población total, la más frecuente causa de muerte es la enfermedad vascular del injerto/muerte súbita (19,7\%), seguida de las infecciones (16,5\%), el fallo primario del injerto 14,3\%) y las neoplasias $(12,5 \%)$ (figura 20). Las causas de fallecimiento cambian según el tiempo postrasplante que se considere (figura 20). En el primer mes postrasplante, casi el $50 \%$ de los fallecimientos se producen por fallo primario del injerto. Después del primer mes y hasta cumplir el primer año, el rechazo agudo $(15,6 \%)$ y sobre todo las infecciones $(35,4 \%)$ son la principal causa de muerte. Después del primer año, la causa mayoritaria son las distintas manifestaciones de la enfermedad vascular del injerto $(29,5 \%)$ y los tumores $(21,3 \%)$. Con el paso del tiempo, las principales causas de muerte en el primer año han cambiado significativamente, con incremento de los fallecimientos por fallo primario del injerto y disminución de las ocurridas por rechazo agudo (figura 21). Sin embargo, en las muertes ocurridas entre el primer y el quinto año después del trasplante, solo se ha observado una disminución significativa de las ocurridas por enfermedad vascular del injerto/muerte súbita y una tendencia al aumento de las muertes por rechazo agudo (figura 22).

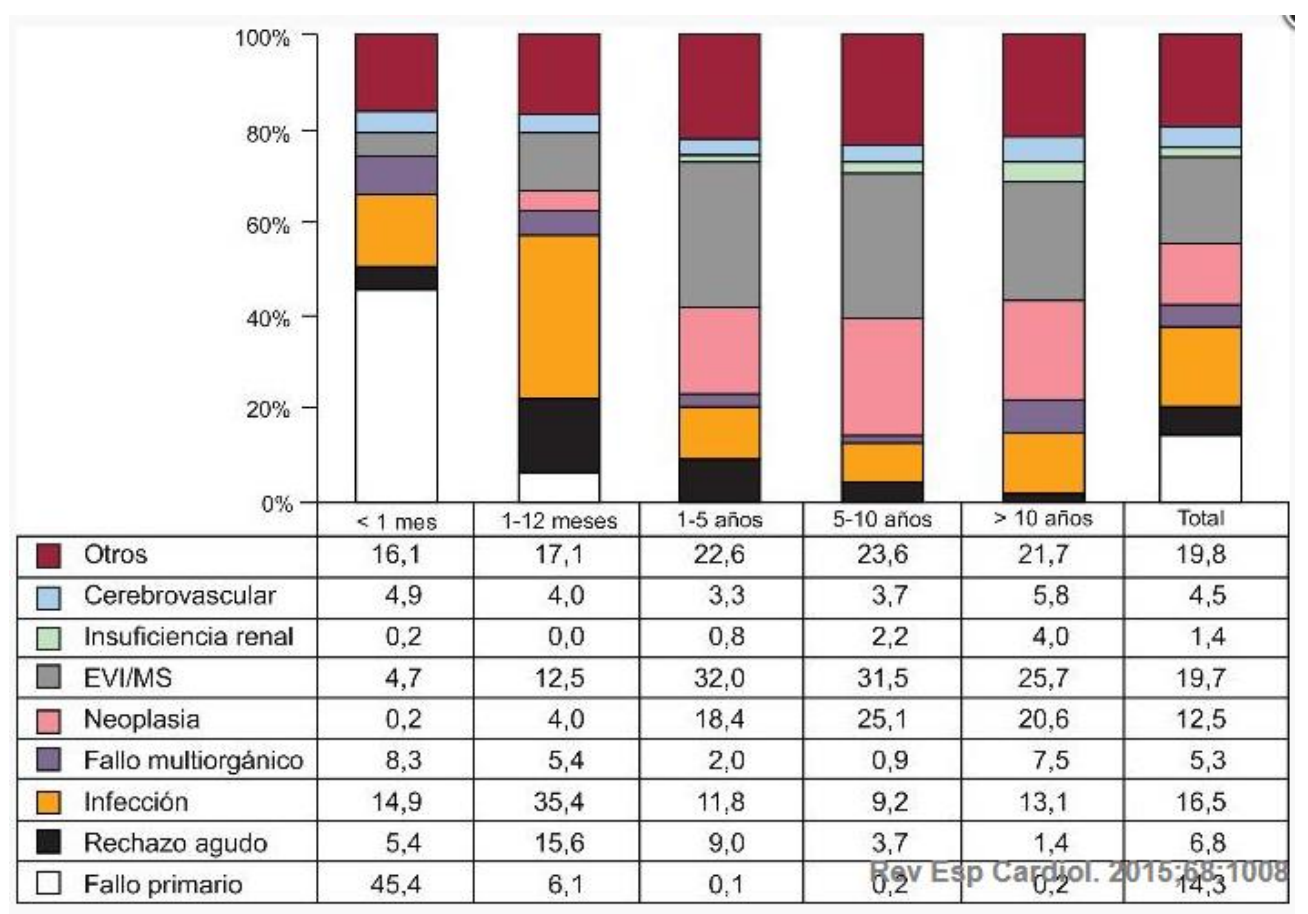

Figura 20. Causas de muerte según tiempo desde el trasplante y en toda la serie (1984-2014). EVI: enfermedad vascular del injerto; MS: muerte súbita. 


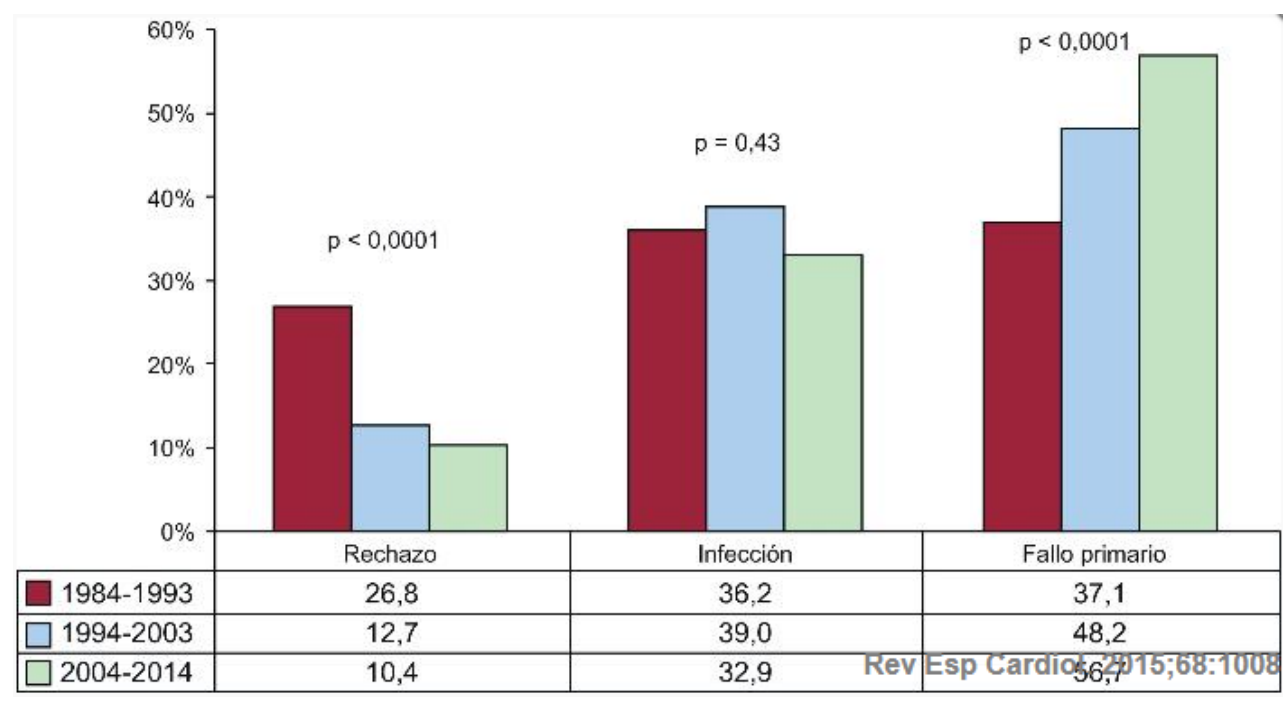

Figura 21. Causas de muerte el primer año después del trasplante en la serie total (1984-2014).

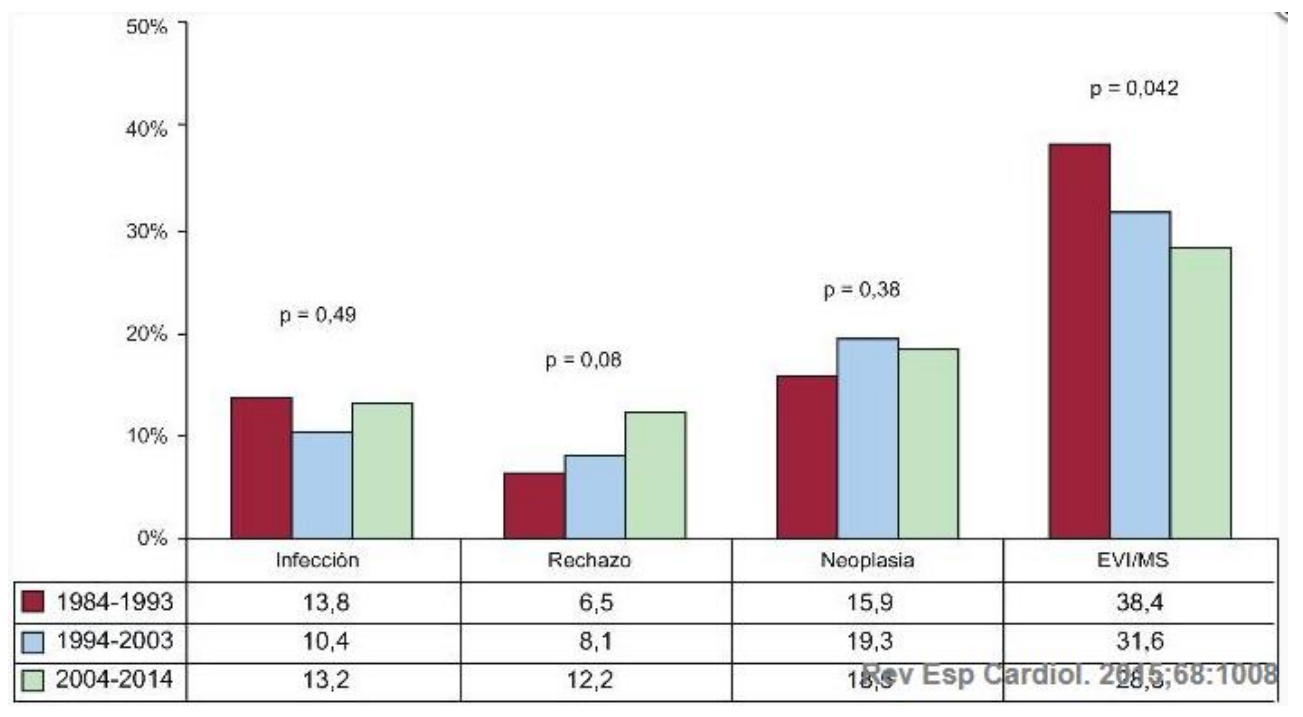

Figura 22. Causas de las muertes ocurridas entre el primer y el quinto año después del trasplante en la serie total (1984-2014). EVI: enfermedad vascular del injerto; MS: muerte súbita. 


\section{DISCUSIÓN}

La actividad del trasplante cardiaco en España durante 2014 se ha mantenido estable respecto a los últimos años, después de la disminución apreciada desde principios del presente siglo. Asimismo, se confirma la tendencia en las características del procedimiento que viene observándose desde el lustro previo, con un perfil clínico de los receptores complejo, elevada proporción de trasplantes urgentes, un alto porcentaje de donantes subóptimos y tiempos de isquemia relativamente largos. Pese a este entorno en general desfavorable, los equipos españoles han mantenido los resultados en mortalidad e incluso empieza a observarse una tendencia a la mejora en el seguimiento a medio plazo.

Aproximadamente 1 de cada 5 trasplantes en España se realiza a un receptor con algún dispositivo de asistencia circulatoria, repartidos equitativamente entre ECMO y dispositivos de asistencia circulatoria (pulsátil o, principalmente, continua). El uso creciente de la asistencia circulatoria previa al trasplante es una tendencia universal, tal como muestran los datos del registro de la International Society for Heart and Lung Transplantation ${ }^{26}$, y en España ha comenzado a ser una práctica frecuente a partir de 2009 . El presente análisis revela que la estabilización de los pacientes más graves con dispositivos de asistencia ventricular consigue unos excelentes resultados precoces y a medio plazo, muy próximos a los que se obtienen en trasplantes electivos. Sin embargo, en esta serie el pronóstico de los receptores asistidos con ECMO resulta significativamente más desfavorable, hallazgo similar al de los análisis realizados en otras poblaciones ${ }^{27}, 28$. Todos estos hallazgos parecen indicar que el uso de ECMO probablemente sea más apropiado como puente a la decisión que como puente al trasplante en sí mismo, en cuyo caso se debe escalar a un dispositivo de más larga duración.

Cambios significativos son también evidentes en las características de los donantes. Particularmente, el aumento de la edad del donante y la proporción de los donantes considerados subóptimos (edad > 45 años) han presentado un incremento progresivo desde los primeros años de actividad. En 2014 se ha llegado al pico de edad del donante, con una media de 44 años y un 54\% de donantes subóptimos. Esto refleja el esfuerzo de los grupos españoles por ofrecer una alternativa terapéutica de gran impacto clínico en una era de relativa escasez de donantes y empeoramiento de su condición. No obstante, hay que tener muy en cuenta el impacto pronóstico de esta variable a la hora de analizar los resultados de los programas, especialmente a medio y largo plazo.

El análisis de las curvas de supervivencia muestra que, a pesar del contexto clínico más complejo actual, la mortalidad precoz sigue en niveles similares a los de periodos anteriores y es superponible a la reportada en el registro internacional en periodos similares ${ }^{26}$. Es destacable asimismo que los pacientes trasplantados en el último decenio presentan a partir del tercer-cuarto año una casi significativa mejor supervivencia que los pacientes trasplantados en la década inmediatamente anterior. Un análisis de las causas de muerte puede aportar algunas claves para estos hallazgos. Durante el primer año ha aumentado significativamente la proporción de muertes por fallo primario del injerto, lo cual no resulta sorprendente atendiendo a las peores condiciones de los receptores en el momento del trasplante (uso todavía amplio de ECMO como soporte circulatorio en lugar de dispositivos de asistencia ventricular ${ }^{29}, 30$, peores condiciones hemodinámicas $^{31}$, alargamiento de los tiempos de isquemia y uso de donantes subóptimos). Este incremento se compensa, no obstante, con un control más adecuado de los rechazos agudos graves, que han pasado como causa de muerte de un $27 \%$ en la primera década de la serie a un $10 \%$ en la última, sin un aumento de las infecciones mortales (debido a la mejora del diagnóstico, la profilaxis y el tratamiento de estas). En las muertes acaecidas entre el primer y el quinto año, se constata una disminución significativa de las debidas a enfermedad vascular del injerto y muerte súbita (una manifestación frecuente de la enfermedad vascular en este periodo postrasplante). Sin duda, los grupos españoles practican una estrategia diagnóstica más agresiva de esta grave y limitante complicación después del trasplante, y sobre todo la implementación de tratamientos de reconocido efecto en esta enfermedad, como el uso universal de estatinas desde el mismo momento del trasplante y una inmunosupresión individualizada. En cuanto a esta, hay que destacar el uso predominante de tacrolimus como inhibidor de la calcineurina, que posee una acción diferencial respecto a la ciclosporina sobre la microvasculopatía y el remodelado de coronarias epicárdicas del injerto ${ }^{32}$ y sobre el perfil de riesgo cardiovascular $^{33}$. Lo mismo puede aplicarse al uso del micofenolato respecto a la azatioprina ${ }^{34}$. En este aspecto, particularmente relevante resulta el amplio uso de los inhibidores de mTOR (principalmente

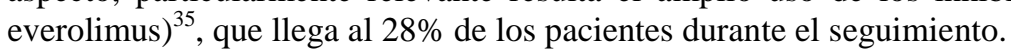




\section{CONCLUSIONES}

La actividad del trasplante cardiaco en España se ha mantenido estable en los últimos años, con alrededor de 250 procedimientos por año. A pesar del empeoramiento y la complejidad del contexto clínico actual (uso de donantes subóptimos, asistencia circulatoria mecánica), los grupos españoles han conseguido mantener los resultados en mortalidad y se apunta a una progresiva mejora del pronóstico a medio plazo.

\section{FINANCIACIÓN}

El Registro Español de Trasplante Cardiaco está parcialmente financiado por una beca no condicionada de Novartis.

\section{CONFLICTO DE INTERESES}

F. González-Vílchez recibe remuneración por participar en el comité de control y análisis estadístico de Roche y Astellas y por ponencias, presentaciones educativas y gastos de viaje de Roche, Astellas y Novartis. A. Villa es beneficiario de una beca de St. Jude Medical y ha recibido remuneración por ponencias y presentaciones educativas de St. Jude Medical. J. Segovia ha recibido remuneración por ponencias y presentaciones educativas por Novartis y Roche.

\section{AGRADECIMIENTOS}

Agradecemos el soporte estadístico dado por ODDS, S.L. 


\section{Anexo. COLABORADORES DEL REgISTRO ESPAÑOL DE TRASPLANTE CARDIACO (1984-2014)}

\begin{tabular}{|c|c|}
\hline Clínica Universitaria Puerta de Hierro, Majadahonda, Madrid & $\begin{array}{l}\text { Manuel Gómez-Bueno, Francisco Hernández Pérez, Luis Alonso- } \\
\text { Pulpón, Alberto Forteza Gil, Santiago Serrano-Fiz, Raúl Burgos } \\
\text { Lázaro, Carlos García Montero y Evaristo Castedo Mejuto }\end{array}$ \\
\hline Hospital Universitario y Politécnico La Fe, Valencia & $\begin{array}{l}\text { Ignacio Sánchez-Lázaro, Luis Martínez-Dolz, Mónica Cebrián } \\
\text { Pinar y Soledad Martínez Penades }\end{array}$ \\
\hline Hospital Universitario de A Coruña, A Coruña & $\begin{array}{l}\text { María J. Paniagua-Martín, Eduardo Barge-Caballero, José J. } \\
\text { Cuenca-Castillo, Francisco Estévez-Cid y Gonzalo Barge-Caballero }\end{array}$ \\
\hline Hospital Universitario Reina Sofía, Córdoba & Amador López-Granados y Juan Carlos Castillo-Diéguez \\
\hline Hospital Universitario Marqués de Valdecilla, Santander & $\begin{array}{l}\text { Manuel Cobo, Miguel Llano-Cardenal, José A. Vázquez de Prada y } \\
\text { Francisco Nistal Herrera }\end{array}$ \\
\hline Hospital Gregorio Marañón (adultos), Madrid & $\begin{array}{l}\text { Manuel Martínez Sellés, Juan Fernández-Yáñez, Iago Sousa y } \\
\text { Pablo Díez }\end{array}$ \\
\hline Hospital Universitario 12 de Octubre, Madrid & Miguel Ángel Gómez Sánchez y Laura Morán Fernández \\
\hline Hospital de la Santa Creu i Sant Pau, Barcelona & Viçens Brossa, Sònia Mirabet y Laura López \\
\hline Hospital Universitario Virgen del Rocío, Sevilla & Diego Rángel Sousa y José Manuel Sobrino \\
\hline $\begin{array}{l}\text { Hospital Universitario de Bellvitge, L'Hospitalet de Llobregat, } \\
\text { Barcelona }\end{array}$ & Nicolás Manito, Josep Roca-Elías y Joel Salazar-Mendiguchía \\
\hline Clínica Universitaria de Navarra, Pamplona & Cristian Delgado Domínguez e Ignacio Bibiloni Lage \\
\hline Hospital Clínic Universitari, Barcelona & M. Ángeles Castel, Marta Farrero y Ana García-Álvarez \\
\hline Hospital Universitario Central de Asturias, Oviedo & $\begin{array}{l}\text { José Luis Lambert, Beatriz Díez de Molina y María José Bernardo } \\
\text { Rodríguez }\end{array}$ \\
\hline Hospital Universitario Gregorio Marañón (infantil), Madrid & Manuela Camino y Constancio Medrano \\
\hline $\begin{array}{l}\text { Hospital Universitario Virgen de la Arrixaca, El Palmar, } \\
\text { Murcia }\end{array}$ & $\begin{array}{l}\text { Domingo Pascual-Figal, Iris Garrido-Bravo y Francisco Pastor } \\
\text { Pérez }\end{array}$ \\
\hline Hospital Universitario Miguel Servet, Zaragoza & Teresa Blasco-Peiró, Marisa Sanz-Julvé y Ana Pórtoles Ocampo \\
\hline Hospital Clínico Universitario, Valladolid & $\begin{array}{l}\text { Luis de la Fuente Galán, Javier López Díaz y Ana María Correa } \\
\text { Fernández }\end{array}$ \\
\hline Hospital Universitario La Paz, Madrid & Luis Guereta, Luz Polo y Carlos Labrandero \\
\hline Hospital Universitario Vall d'Hebron, Barcelona & Dimpna C. Albert Brotons, Ferrán Gran Ipiña y Raúl Abella \\
\hline
\end{tabular}

\section{Bibliografía}

1. Vázquez de Prada JA. Registro Español de Trasplante Cardiaco. Primer Informe Oficial. Rev Esp Cardiol. 1991;44:293-6.

2. Vázquez de Prada JA. Registro Español de Trasplante Cardiaco. Segundo Informe Oficial 1991. Rev Esp Cardiol. 1992;45:5-8.

3. Arizón JM, Segura J, Anguita M, Vázquez de Prada JA. Registro Español de Trasplante Cardiaco. Tercer Informe Oficial. Rev Esp Cardiol. 1992;45:618-21.

4. Arizón del Prado JM. Registro Español de Trasplante Cardiaco. Cuarto Informe Oficial (1984-1992). Rev Esp Cardiol. 1993;46:791-5.

5. Arizón del Prado JM. Registro Español de Trasplante Cardiaco. Quinto Informe Oficial (1984-1993). Rev Esp Cardiol. 1994;47:791-5.

6. Arizón del Prado JM. Registro Español de Trasplante Cardiaco. Sexto Informe Oficial (1984-1994). Rev Esp Cardiol. 1995;48:792-7.

7. Arizón del Prado JM. Registro Español de Trasplante Cardiaco. Séptimo Informe Oficial (1984-1995). Rev Esp Cardiol. 1996;49:781-7.

8. Arizón del Prado JM. Registro Español de Trasplante Cardiaco. VIII Informe Oficial (1984-1996). Rev Esp Cardiol. 1997;50:826-32.

9. Almenar Bonet L. Registro Español de Trasplante Cardiaco. IX Informe Oficial (1984-1997). Rev Esp Cardiol. 1999;52:153-8.

10. Almenar Bonet L. Registro Español de Trasplante Cardiaco. X Informe Oficial (1984-1998). Rev Esp Cardiol. 1999;52:1121-9.

11. Almenar Bonet L. Registro Español de Trasplante Cardiaco. XI Informe Oficial (1984-1999). Rev Esp Cardiol. 2000;53:1639-45.

12. Almenar Bonet L. Registro Español de Trasplante Cardiaco. XII Informe Oficial (1984-2000). Rev Esp Cardiol. 2001;54:1305-10. 
13. Almenar Bonet L. Registro Español de Trasplante Cardiaco. XIII Informe Oficial de la Sección de Trasplante Cardíaco de la Sociedad Española de Cardiología (Años 1984-2001). Rev Esp Cardiol. 2002;55:1286-92.

14. Almenar Bonet L. Registro Español de Trasplante Cardiaco. XIV Informe Oficial de la Sección de Insuficiencia Cardíaca, Trasplante Cardíaco y Otras Alternativas Terapéuticas de la Sociedad Española de Cardiología (19842002). Rev Esp Cardiol. 2003;56:1210-7.

15. Almenar Bonet L. Registro Español de Trasplante Cardiaco. XV Informe Oficial de la Sección de Insuficiencia Cardíaca, Trasplante Cardíaco y Otras Alternativas Terapéuticas de la Sociedad Española de Cardiología (19842003). Rev Esp Cardiol. 2004;57:1197-204.

16. Almenar Bonet L. Registro Español de Trasplante Cardiaco. XVI Informe Oficial de la Sección de Insuficiencia Cardíaca, Trasplante Cardíaco y Otras Alternativas Terapéuticas de la Sociedad Española de Cardiología (19842004). Rev Esp Cardiol. 2005;58:1310-7.

17. Almenar Bonet L. Registro Español de Trasplante Cardiaco. XVII Informe Oficial de la Sección de Insuficiencia Cardiaca, Trasplante Cardiaco y Otras Alternativas Terapéuticas de la Sociedad Española de Cardiología (19842005). Rev Esp Cardiol. 2006;59:1283-91.

18. Almenar Bonet L. Registro Español de Trasplante Cardiaco. XVIII Informe Oficial de la Sección de Insuficiencia Cardiaca, Trasplante Cardiaco y Otras Alternativas Terapéuticas de la Sociedad Española de Cardiología (19842006). Rev Esp Cardiol. 2007;60:1177-87.

19. Almenar Bonet L. Registro Español de Trasplante Cardiaco. XIX Informe Oficial de la Sección de Insuficiencia Cardiaca, Trasplante Cardiaco y Otras Alternativas Terapéuticas de la Sociedad Española de Cardiología (19842007). Rev Esp Cardiol. 2008;61:1178-90.

20. Almenar Bonet L. Registro Español de Trasplante Cardiaco. XX Informe Oficial (1984-2008). Rev Esp Cardiol. 2009;62:1286-96.

21. Almenar L, Segovia J, Crespo-Leiro MG, Palomo J, Arizón JM, González-Vílchez F, et al. Registro Español de Trasplante Cardiaco. XXI Informe Oficial de la Sección de Insuficiencia Cardiaca y Trasplante Cardiaco de la Sociedad Española de Cardiología (1984-2009). Rev Esp Cardiol. 2010;63:1317-28.

22. Almenar L, Segovia J, Crespo-Leiro MG, Palomo J, Arizón JM, Cobo M, et al. Registro Español de Trasplante Cardiaco. XXII Informe Oficial de la Sección de Insuficiencia Cardiaca y Trasplante Cardiaco de la Sociedad Española de Cardiología (1984-2010). Rev Esp Cardiol. 2011;64:1138-46.

23. Almenar L, Segovia J, Crespo-Leiro MG, Palomo J, Arizón JM, González-Vílchez F, et al. Registro Español de Trasplante Cardiaca. XXIII Informe Oficial de la Sección de Insuficiencia Cardiaca y Trasplante Cardiaco de la Sociedad Española de Cardiología (1984-2011). Rev Esp Cardiol. 2012;65:1030-8.

24. González-Vílchez F, Gómez-Bueno M, Almenar L, Crespo-Leiro MG, Arizón JM, Martínez-Sellés M, et al. Registro Español de Trasplante Cardiaco. XXIV Informe Oficial de la Sección de Insuficiencia Cardiaca y Trasplante Cardiaco de la Sociedad Española de Cardiología (1984-2012). Rev Esp Cardiol. 2013;66:973-82.

25. González-Vílchez F, Gómez-Bueno M, Almenar L, Crespo-Leiro MG, Arizón JM, Palomo J, et al, en representación de los Equipos Españoles de Trasplante Cardiaco. Registro Español de Trasplante Cardiaco. XXV Informe Oficial de la Sección de Insuficiencia Cardiaca y Trasplante Cardiaco de la Sociedad Española de Cardiología (1984-2013). Rev Esp Cardiol. 2014;67:1039-51.

26. Lund LH, Edwards LB, Kucheryavaya AY, Dipchand AI, Benden C, Christie JD, et al. The Registry of the International Society for Heart and Lung Transplantation: Thirtieth Official Adult Heart Transplant Report2013;Focus Theme: Age. J Heart Lung Transplant. 2013;32:951-64.

27. Kirklin JK, Naftel DC, Pagani FD, Kormos RL, Stevenson LW, Blume ED, et al. Sixth INTERMACS annual report: A 10,000-patient database. J Heart Lung Transplant. 2014;33:555-64.

28. Weiss ES, Allen JG, Arnaoutakis GJ, George TJ, Russell SD, Shah AS, et al. Creation of a quantitative recipient risk index for mortality prediction after cardiac transplantation (IMPACT). Ann Thorac Surg. 2011;92:914-21.

29. KilicA, Allen JG, Weiss ES. Validation of the United States-derived Index for Mortality Prediction after Cardiac Transplantation (IMPACT) using international registry data. J Heart Lung Transplant. 2013;32:492-8.

30. Barge-Caballero E, Almenar-Bonet L, Villa-Arranz A, Pérez-Villa F, Segovia-Cubero J, Delgado-Jiménez J, et al. Impact of short-term mechanical circulatory support with extracorporeal devices on postoperative outcomes after emergency heart transplantation: data from a multi-institutional Spanish cohort. Int J Cardiol. 2014;176:8693.

31. Cosío Carmena MD, Gómez Bueno M, Almenar L, Delgado JF, Arizón JM, González Vilchez F, et al. Primary graft failure after heart transplantation: characteristics in a contemporary cohort and performance of the RADIAL risk score. J Heart Lung Transplant. 2013;32:1187-95.

32. Petrakopoulou P, Anthopoulou L, Muscholl M, Klauss V, Von Scheidt W, Uberfuhr P, et al. Coronary endothelial vasomotor function and vascular remodeling in heart transplant recipients randomized for tacrolimus or cyclosporine immunosuppression. J Am Coll Cardiol. 2006;47:1622-9.

33. Kobashigawa JA, Patel J, Furukawa H, Moriguchi JD, Yeatman L, Takemoto S, et al. Five-year results of a randomized, single-center study of tacrolimus vs microemulsion cyclosporine in heart transplant patients. J Heart Lung Transplant. 2006;25:434-9.

34. Kaczmarek I, Ertl B, Schmauss D, Sadoni S, Knez A, Daebritz S, et al. Preventing cardiac allograft vasculopathy: long-term beneficial effects of mycophenolate mofetil. J Heart Lung Transplant. 2006;25:550-6.

35. Kobashigawa JA, Pauly DF, Starling RC, Eisen H, Ross H, Wang SS, et al, A2310 IVUS Substudy Investigators. Cardiac allograft vasculopathy by intravascular ultrasound in heart transplant patients: substudy from the Everolimus versus mycophenolate mofetil randomized, multicenter trial. JACC Heart Fail. 2013;5:389-99. 